\title{
El capital inmobiliario-financiero y la producción de la ciudad latinoamericana hoy
}

\author{
Financial-real estate capital and the production \\ of the Latin American city today
}

Lisett Márquez López [I]

\begin{abstract}
Resumen
Entre los cambios generados por el tránsito del patrón de acumulación con intervención estatal al neoliberal en América Latina, destacan la consolidación del capital financiero como actor dominante en la economía, la liberación de sus flujos internacionales y el avance de su fusión con el capital inmobiliario en las ciudades. Esta forma del capital ha generado nuevos productos materiales como la vivienda periférica de interés social y/o desarrollos inmobiliarios para la renovación de las áreas centrales altamente valorizadas, la mercantilización y terciarización de la vida urbana, y aumenta los instrumentos financieros especulativos y de riesgo. El protagonismo del capital inmobiliario-financiero ha llevado al debilitamiento de la planeación urbana indicativa, sustituida por una "estratégica" y los gobiernos locales aplican políticas para facilitar su acción.
\end{abstract}

Palabras clave: capital inmobiliario-financiero; políticas urbanas estatales; corredores urbanos terciarios; ciudades latinoamericanas.

\begin{abstract}
Among the changes generated by the transition of the accumulation pattern with state intervention to the neoliberal pattern in Latin America, we highlight the consolidation of financial capital as a dominant economic player, the release of its international flows, and the progress of its merger with real estate capital in the cities. This form of capital has generated new material products such as peripheral social interest housing and/or real estate developments for the renovation of highly valued central areas, commodification and tertiarization of urban life, while speculative and risky financial instruments multiply. The financial-real estate capital's prominence has led to the weakening of indicative urban planning, replaced by a "strategy", and local governments apply policies to facilitate its action.
\end{abstract}

Keywords: financial-real estate capital; state urban policies; tertiary urban corridors; Latin American cities. 


\section{Introducción: la formación del capital bancario y financiero}

Aunque existen antecedentes como la Banca de los Caballeros Templarios que operó en los siglos XII a XIV, la historia de los bancos, en el sentido actual de institución para el depósito dinerario y la acumulación mediante el crédito y sus intereses, se inició en el siglo XIV en el norte de Italia, siendo la Banca Médici la que logró la mayor importancia. Desde allí, la banca se expandió a toda Europa, alcanzando un gran desarrollo en los Países Bajos (Ámsterdam), en el siglo XVI, y en Inglaterra (Londres), un siglo después. Los empréstitos otorgados por los banqueros alemanes fueron esenciales en la colonización de América Latina bajo los imperios de Carlos V y Felipe II de España y Alemania. En 1602, la Compañía Neerlandesa de las Indias Orientales fundó la primera Bolsa de Valores conocida (Colling, 1965).

A partir de la revolución industrial europea (1760-1840), los créditos de la banca sirvieron para la expansión acelerada de la industria, su concentración monopólica, y la paulatina fusión de ambos sectores para formar el capital financiero a finales del siglo XIX e inicios del XX, el cual siguió financiando a todos los sectores del capital. Durante las décadas del veinte y treinta, en casi todos los países de desarrollo medio, se impulsaron reformas financieras y se crearon bancos centrales. En México, durante el Imperio de Maximiliano se fundó el Banco de Londres y México en 1864, y el Banco de México en 1925; la Bolsa de México se creó en 1939, en tanto que el mayor desarrollo del sector ocurrió durante la 2a Guerra Mundial (19411945) (López y Rougier, 2018; Carnet, 1990)
La penetración del capital bancariofinanciero en la vida cotidiana de la población se inició con la invención de la tarjeta de crédito que, luego de un intento en 1914, realizado por Western Unión, se generalizó a partir de la tarjeta Diner's Club creada en 1949, la cual apareció en México en 1953 y fue seguida por American Express y Carte Blanche. La primera tarjeta bancaria de crédito mexicana fue introducida por Banamex en 1968, y hoy se encuentra en gran parte de las billeteras de los mexicanos, como medio para adquirir, a crédito, los bienes para su reproducción (Carnet, 1990). En México se reconoció formalmente al capital financiero en 1970. La crisis de 1982, llevó a la estatización de la banca mexicana en quiebra, la cual fue nuevamente privatizada en 1990 y sufrió su peor crisis en 1994, cuando fue rescatada por el gobierno mediante un multimillonario endeudamiento público (Fobaproa - Fondo Bancario de Protección al Ahorro). Hoy, el capital financiero, conformado por múltiples organismos privados con una participación mayoritaria del capital extranjero, es la fracción dominante del capital, omnipresente en la vida económica de las familias, las empresas, las instituciones y el Estado.

\section{La crisis del capitalismo y la hegemonía del capital financiero a finales del siglo XX}

Después del largo periodo de expansión económica de la 2 a posguerra mundial (1945-1970), la economía de los países capitalistas hegemónicos empezó a debilitarse, enfrentando durante la década de los setenta 
una severa desaceleración, cuyos efectos a escala mundial se sumaron a la crisis de la deuda externa de los países latinoamericanos y otros, debido al fin del masivo acceso al crédito externo barato, alimentado por el capital sobreacumulado liberado por el boom petrolero (petrodólares, eurodólares), y la recesión de los países hegemónicos e introducido al mercado financiero mundial, dando lugar a una grave crisis económica mundial en 1982. Esta profunda recesión impactó negativamente en el patrón de acumulación de capital con intervención estatal y en la política de industrialización por sustitución de importaciones, que desde la década de los cuarenta actuaban como motores de la industrialización en las principales ciudades latinoamericanas e impulsaban su desarrollo económico y su expansión demográfica y física acelerada; así, ambos llegaron a su fin (Pradilla, 2009).

Con el objetivo de contrarrestar el bajo crecimiento económico y la alta volatilidad monetario-financiera, los Estados Unidos de América e Inglaterra iniciaron el proceso de desregulación y liberación de sus sistemas financieros, procesos que fueron seguidos por Canadá y otros países industrializados, así como por países en desarrollo o emergentes, incluidos los latinoamericanos (López y Bustamante, 2013), como parte de la implantación de un nuevo modelo económico neoliberal que sustituyó al de intervención estatal.

Mediante criterios impuestos por el Fondo Monetario Internacional y el Banco Mundial, se acentuó el proceso de apertura comercial hacia el exterior e impulsó una nueva dinámica económica basada en la lógica del libre mercado, aplicada en los países inmersos en el proceso de globalización, entre ellos los latinoamericanos. Se aplicaron políticas neoliberales emanadas del llamado Consenso de Washington, como el recorte de funciones del Estado, la rápida privatización de empresas públicas, incluidos los bancos estatizados en la crisis de 1982, y la entrada de bancos extranjeros, la libre circulación de capitales, mercancías y servicios, la privatización y desregulación de los fondos de pensiones de los trabajadores, la proliferación de productos e instrumentos financieros operados mediante las nuevas tecnologías de la información y comunicación y la flexibilización de la fuerza laboral en la producción y otros sectores económicos. Estos cambios transformaron el papel y la forma de operar de los mercados financieros y crearon las condiciones favorables para realizar negocios a nivel global, hasta llegar a que el capital financiero consolidara su papel dominante en la economía mundial (Guillén, 1997).

La configuración de la nueva lógica neoliberal, dominada por la financiarización, ${ }^{1}$ se ha caracterizado por la presencia de estrategias financieras tales como la actuación de las bolsas de valores como actor central en la dinámica económica mundial, la transformación del sistema bancario y su vinculación con la creación de nuevos productos, servicios e instrumentos financieros cada vez más sofisticados, y el flujo de fondos hacia los mercados a través de la creciente participación de instituciones financieras: compañías de seguros, fondos de inversión, de pensiones, de capital de riesgo, de cooperación colectiva o crowdfunding, etc., (Sassen, 1999; De Mattos, 2016; 2018), así como de inversión y desarrollo inmobiliario y otros instrumentos ficticios. 
Si bien los mercados bancarios siguen cumpliendo las funciones tradicionales de oferta y demanda de dinero, las innovaciones financieras han tenido una importante expansión mediante la libre circulación de los capitales y la creación de nuevos mercados utilizando acciones presentes en las bolsas de valores de otros países considerados con mejores relaciones precio-ganancia, o en el caso de los emisores permitiendo tener acceso a fondos abundantes y nuevas oportunidades de inversión por lo general altamente especulativas (Sassen, 1999). Este proceso de financiarización, indujo el debilitamiento del papel económico de las inversiones industriales, para centrarse en las ganancias provenientes de las actividades financieras, tanto de operaciones especulativas como de la expansión del crédito hacia otros sectores altamente rentables como el crédito al consumo y el hipotecario (Huerta y Kala, 2013), actividades económicas que son más rentables, pero menos productivas; luego de tres décadas de operación, la financiarización ha propiciado impactos importantes como la desindustrialización y la terciarización de las principales ciudades industriales latinoamericanas, generando un menor dinamismo en la economía (Márquez, 2005; Márquez y Pradilla, 2008).

En la región, la terciarización está dominada por la informalidad, pues una de las circunstancias producidas por el neoliberalismo ha sido la reducción del empleo formal y el incremento de la masa de una superpoblación relativa que sobrevive mediante la realización de actividades informales (comercio en la vía pública, servicios personales de todo tipo, venta del cuerpo, delincuencia individual u organizada, y otras), visibles en las principales vialidades, plazas, parques, corredores comerciales, así como en los puntos de concentración de la población: hospitales, universidades, colegios, estaciones de transporte público, etc., y que busca al mismo tiempo la solución a sus necesidades de vivienda mediante la ocupación periférica irregular, la auto construcción y la densificación de los viejos barrios populares o el subarriendo en estas viviendas.

\section{La articulación del capital financiero con el inmobiliario y su participación en la producción de la ciudad en América Latina}

En el contexto de la financiarización general de la economía capitalista, el capital inmobiliario, históricamente ligado al financiero, encontró a escala mundial y en particular en las grandes metrópolis, un ámbito apropiado para su reproducción, más abierto, flexible y menos regulado que en el pasado.

Según la teoría marxista, el objetivo principal del capitalismo es generar y acumular plusvalor (beneficio); por ello, los capitalistas, al final del ciclo de rotación del capital, cuando la mercancía se transforma nuevamente en dinero, reparten la plusvalía obtenida entre los participantes, cada uno de los cuales retiene una parte de ella para continuar la acumulación y el resto lo dedican a su consumo. Cuando existe un exceso de acumulación, se produce un excedente de capital ocioso, una sobreacumulación, para 
la que el capitalismo se ve en la necesidad de encontrar campos rentables para su absorción en la producción de nueva plusvalía (Harvey, 2013, p. 22). En las ciudades, por su dinamismo, capacidad de crecimiento y de constante renovación, los capitalistas han encontrado un lugar privilegiado para la revalorización del capital sobreacumulado en otros sectores.

Las ciudades, como afirma Topalov (1979, p. 75), son un espacio en el cual se reúnen las condiciones generales de la producción y de la circulación, así como las de la reproducción de la fuerza de trabajo y de los no trabajadores, pero también son un conjunto complejo de mercancías inmobiliarias producidas con destino a la obtención de ganancia: viviendas, edificios de oficinas, comercios, industrias, lugares recreativos, etc.; todas ellas, cuando son producidas por el capital, sirven para su valorización. El crecimiento físico, demográfico y económico de las ciudades exige y permite generar constantemente nuevos soportes materiales y/o reconstruir los existentes mediante su destrucción y la producción de otros nuevos, cada vez más adecuados a las necesidades emergentes y a las tecnologías en boga (Pradilla, 2018).

El proceso de construcción de lo urbano presenta dos características particulares de producción. La primera es que cada proceso productivo requiere de suelo nuevo o reutilizado para su edificación, lo que lo hace un ensamblaje en el sitio, en el que el tiempo de transformación del capital en mercancía puede demorar meses o años, dependiendo de la magnitud y complejidad de la construcción y de la eficiencia de su forma de producción; en general, su periodo de producción es muy largo, en comparación con otras ramas industriales, lo que implica inmovilizar el capital adelantado invertido en el proceso productivo durante un largo período de tiempo, antes de su recuperación en la venta del inmueble. El capital bancariofinanciero suministra al inmobiliario este capital adelantado para la fase de la construcción.

Las formas productivas actuales en Latinoamérica son: la autoconstrucción precapitalista, la producción por encargo mercantil simple, y la promoción-producción inmobiliaria capitalista semi-industrializada caracterizada por ser realizada por constructores mercantiles capitalistas, en terrenos adquiridos en el mercado formal, dotados de infraestructura y servicios, construida con instrumentos de trabajo técnicamente complejos, mano de obra asalariada y materiales de construcción industrial, bajo el control técnico y social del capital; ésta última es hoy considerada la forma de producción dominante en las grandes ciudades, y ha encontrado en ellas un campo importante de acción y acumulación de capital con la creación de nuevos productos: vivienda de lujo con amenidades interiores, centros comerciales, complejos de oficinas corporativas, centros de recreación, hoteles, conjuntos habitacionales cerrados, desarrollos de usos mixtos, etc., característicos del capitalismo neoliberal (Pradilla, 2018, pp. 160-163).

El proceso de producción y la circulación del capital bajo la forma mercancía en el sector inmobiliario, es compleja y requiere de mucho tiempo: incluye la inversión de capital para la adquisición y adecuación del 
terreno, el proceso de diseño, la construcción y la promoción hasta su finalización y venta. El ciclo sólo termina cuando el comprador adquiere el inmueble y reembolsa totalmente el capital al promotor. Los elevados costos de todas las etapas hacen necesaria la intervención del capital bancariofinanciero nacional o transnacional, el cual estará presente en todas las actividades que intervienen en el ciclo inmobiliario, financiando la adquisición del terreno, el proceso de diseño y construcción de la obra, la promoción y comercialización del inmueble, así como en el otorgamiento de créditos inmobiliarios a largo plazo - 10, 20 o más años -, dirigidos a los compradores (Topalov, 1979) con el objetivo de que el promotorproductor recupere inmediatamente el capital comprometido en la operación, más una ganancia, y pueda reiniciar el ciclo productivo. Esta es la segunda particularidad de la producción capitalista de inmuebles.

La relación entre el sector inmobiliario y el financiero a partir de la integración neoliberal global de los mercados, incluida la modificación del marco normativo financiero, la multiplicación de los instrumentos y la aplicación de las nuevas tecnologías, se ha hecho más cercana, encontrado mayor facilidad para la compra y el intercambio de propiedades y créditos inmobiliarios, mediante la transformación de los inmuebles o fracciones de ellos en activos financieros representados en documentos bancarios y de valores, la llamada titularización o securitización (Parnreiter, 2018, pp. 441 y ss.; De Mattos, 2016), o la multiplicación de fondos especializados, cotizados o no en la bolsa, que invierten capitales recolectados de diferentes personas morales o físicas (David, 2017, p. 230), dejando a un lado la forma tradicional de obtener recursos.

Por ejemplo, el Fideicomiso de Inversión en Bienes Raíces (FIBRA) mexicano, basado en el modelo del Real Estate Investment Trust creado en Estados Unidos, que mediante la renta o administración de portafolios de bienes inmuebles, permite invertir ya sea a inversionistas particulares y/o institucionales tales como los fondos de pensiones, aseguradoras, afianzadoras, etc., en el desarrollo y producción, renovación, adquisición y/o administración de residencias, oficinas, centros comerciales, hoteles, plantas industriales, etc., a través de la compra de Certificados Bursátiles que cotizan en la Bolsa de Valores, donde la oferta y la demanda determinan el valor de las acciones bursátiles $y$, por tanto, el precio de mercado de las empresas capitalistas, al mismo tiempo que se benefician con exenciones en el pago de impuestos, por lo que son un negocio atractivo para inversionistas nacionales y trasnacionales, que buscan colocar su capital en ciudades con condiciones económicamente más rentables.

Otro esquema, de reciente aplicación en algunas de las principales ciudades de América Latina, es el Crowdfunding inmobiliario o hipotecario, un fondeo colectivo. Mediante el sector inmobiliario, cualquier inversionista pequeño o mediano con una aportación mínima puede invertir colectivamente en la compra y/o administración de un inmueble, mientras que con el hipotecario se presta dinero a personas físicas o jurídicas para que compren una vivienda (Domínguez y otros, 2017). En algunos casos, el inversionista puede 
ser socio del proyecto inmobiliario con un mayor potencial de rendimiento, o participar únicamente en el préstamo para que el desarrollador inmobiliario levante un proyecto a cambio de una tasa de rendimiento menor (Tolentino, 2017).

El sector ofrece retornos mayores a los instrumentos de ahorro e inversión tradicionales. La inversión puede hacerse en cualquier parte del mundo, desde un teléfono móvil o una computadora en una plataforma fácil de usar, donde el interesado puede registrarse, seleccionar el proyecto, el monto a invertir, firmar un convenio en línea y realizar su aportación mediante una transferencia electrónica; incluso puede ver el avance del proyecto y el estado de sus inversiones. Esta inversión es administrada por un banco a través de un fideicomiso y al término del proyecto se paga el porcentaje correspondiente a cada inversionista.

En su mayoría, estas inversiones son dirigidas al financiamiento de desarrollos residenciales y comerciales debido a su amplia demanda. Recientemente, en países como Brasil, Colombia, Chile y México, la economía colaborativa ha empezado a aplicarse en las inversiones inmobiliarias; destaca Bogotá, Colombia, con la construcción del desarrollo inmobiliario de usos mixtos Bogotá Downtown Bacatá, realizado mediante el financiamiento colectivo de 8.000 inversionistas de diversos países que reunieron \$200 millones de dólares en dos años para iniciar la construcción del inmueble. El desarrollo, asentado en el centro de la ciudad, se encuentra a un $95 \%$ de su construcción y alberga dos torres: una, la más alta de Colombia, de 67 pisos y 216 metros de altura, la segunda de 56 pisos y 167 metros, conformadas por 405 departamentos, 117 oficinas, 319 habitaciones de hotel, 6,500 metros cuadrados de uso comercial y 700 estacionamientos (Valencia, 2018).

Desarrollos inmobiliarios como éste son la expresión en el territorio de la generalización de las políticas de financiarización impuestas por el patrón de acumulación neoliberal a nivel mundial, que han llenado las zonas más rentables de las principales ciudades desarrolladas, así como las latinoamericanas - Buenos Aires, Rio de Janeiro y Sao Paulo, Santiago, Bogotá, Ciudad de México -, de nuevos artefactos inmobiliarios o proyectos urbanos homogéneos a nivel mundial, afectando su lógica territorial y su fisonomía.

La simultánea transformación de las instituciones públicas promotoras de la producción de vivienda social en entes de financiamiento hipotecario de sus derechohabientes para la adquisición de viviendas producidas por el capital inmobiliariofinanciero privado ha llevado a la construcción en las periferias urbanas alejadas, para obtener terrenos baratos, de grandes conjuntos de micro viviendas de mala calidad, aisladas, con frecuencia carentes de infraestructuras para la movilidad, servicios públicos y sociales, o equipamientos de vida urbana, lo que ha llevado al abandono de parte considerable de viviendas por sus compradores iniciales. El resultado ha sido un crecimiento excesivo, extensivo, disperso y aislado de la estructura urbana, con los costos sociales que ello implica (Pradilla, 2018). En el caso mexicano, paradigmático en el continente, la banca privada financió el $48.23 \%$ de esta inversión en el segundo semestre de 2017 , y el $45.67 \%$ en el mismo semestre de 2018 (BBVA Research, 2018, p. 13). 
La estrecha relación anudada entre el capital inmobiliario y el financiero, su importancia cuantitativa, así como el carácter abiertamente especulativo del segundo, se puso de manifiesto en la gran recesión económica mundial de 2007-2008, cuyo inicio se ubicó en el boom del sector inmobiliario norteamericano seguido por la insolvencia generalizada de los compradores, que llevó a la proliferación de hipotecas "basura" (subprime) en el mercado financiero y a la trasmisión de la crisis del sector inmobiliario al financiero y por él, a la economía mundial en su conjunto (Parnreiter, 2018, pp. 439 y ss.)

\section{Verticalización, rentas del suelo y capital inmobiliario-financiero}

La aplicación indiscriminada de las políticas neoliberales, incluidas la financiarización de la economía, la desregulación del suelo y la apertura a la inversión urbana extranjera, han sido acompañadas por políticas públicas basadas en teorías, políticas, programas o proyectos urbanos y formas de gestión aplicadas en los países del primer mundo (Pradilla, 2010), e impulsadas por las organizaciones internacionales y el mercado mundial, que si bien buscan atender la expansión urbana acelerada y desordenada de las ciudades, también se compaginan muy bien con los intereses del sector financiero-inmobiliario, en la medida en que en ellos encuentran las condiciones apropiadas para su propio desarrollo.

Por ejemplo, la Nueva Agenda Urbana promovida por la Organización de Naciones
Unidas (ONU), aprobada en la conferencia de Naciones Unidas sobre la Vivienda y el Desarrollo Sostenible (Hábitat III), celebrada en Quito, Ecuador, en 2016, proporciona una guía dirigida a los Estados para promover la creación de ciudades compactas, incluyentes, seguras y sostenibles (ONU, 2017). La mayoría de los gobiernos latinoamericanos ha incluido en sus programas de desarrollo urbano, acciones dirigidas a atender estas recomendaciones.

En el discurso, nuestras ciudades deben ser objeto de la aplicación de proyectos que apuesten por el rescate de los Centros Históricos, la revitalización de los espacios públicos, la reutilización de las áreas urbanizadas, incluidas las zonas industriales abandonadas por el cierre $\mathrm{y} / \mathrm{o}$ salida de industrias, la renovación urbana, la intensificación del uso mixto del suelo mediante su densificación, el aprovechamiento de las redes de transporte, infraestructura, equipamiento y servicios urbanos, orientando a las urbes hacia un modelo más compacto, dinámico, accesible, incluyente y eficiente en el consumo de recursos, con el objetivo de reactivar la vida cotidiana y comercial y, al tiempo, contener la expansión horizontal y la baja densidad en las periferias, mitigando la dispersión y la carencia de infraestructura y servicios urbanos, permitiendo mejorar la calidad de vida de la población, sobre todo la de menores recursos, mediante la accesibilidad a los servicios, la reducción de distancia, tiempo y gastos de transporte y evitando daños al medio ambiente. En la realidad, la Nueva Agenda Urbana se ha convertido en una herramienta en manos de los gobiernos para impulsar la renovación urbana realizada por el gran capital inmobiliario-financiero trasnacional. 
Las principales ciudades en América Latina, se han enfrentado en las últimas dos décadas, a un acelerado e intenso proceso de renovación urbana en las zonas centrales, sobre todo en espacios territorialmente privilegiados. Desarrollar estos proyectos al interior de la trama urbana de las ciudades, requiere disponer de tierra libre o renovar los inmuebles existentes, aunque por lo general, los grandes terrenos son escasos y los que están disponibles son costosos, en parte por sus condiciones de constructibilidad y por sus ventajas de localización, y aunque los predios no se usan productivamente, pueden venderse de acuerdo a las rentas potenciales que pudieran obtener si se involucraran en una actividad económica, incluso el precio del suelo podría ser similar al de los terrenos de características y localización parecidas a las que en ese momento se están explotando (Jaramillo, 2009, p. 257).

Los inmuebles construidos con muchos años de antigüedad, envejecen y se deprecian por la pérdida de valor debido a su uso. En la medida que los inmuebles envejecen, aumenta la relación entre el precio del terreno y el del inmueble; cuando el valor de uso se agota totalmente, todo el precio del inmueble lo constituye el precio del suelo, por ello los inversionistas prefieren demolerlo y construir uno nuevo que le garantice rentabilidad, en muchos casos edificando con mayor intensidad, ya que la construcción en altura permite multiplicar la cantidad de espacio construido, factor que facilita una inversión a largo plazo y amplía la sobreganancia (Jaramillo, 2009, p. 137). Para obtener el terreno, se recurre al juego del mercado, la intervención estatal facilitadora o al despojo mediante la coerción extraeconómica (Harvey,
2007, cap. 4), que implican la salida de los anteriores ocupantes y, aún, el cambio de estratos sociales en el área. La construcción en altura implica costos más elevados que la baja, pues se incrementan en la medida que aumentan los pisos, ya que requieren del uso de técnicas de construcción más avanzadas y de maquinaria pesada y especializada, incluso del diseño en alta tecnología.

El capital inmobiliario financiero, con la acción facilitadora del sector público, ha encontrado en la política de densificación un negocio redituable, mediante la promoción y construcción de novedosos y modernos inmuebles privados en su mayoría de uso terciario, que incluyen: altas torres de oficinas corporativas para grandes empresas nacionales o trasnacionales - soportes materiales de la actividad bancaria y financiera y de la gestión empresarial -, hoteles de gran turismo, centros comerciales, así como desarrollos inmobiliarios verticales y densos de uso mixto que incluyen mega torres de viviendas con departamentos de lujo de pequeñas dimensiones, dotadas de amenidades: alberca, gimnasio, roof garden, salón de usos múltiples, áreas infantiles, entre otras; así como oficinas, hoteles, comercio y servicios, muchos de ellos diseñados por arquitectos de prestigio mundial.

Los gobiernos locales permiten construir estos desarrollos inmobiliarios en zonas céntricas de alto valor comercial y aprovechar intensiva y gratuitamente la infraestructura y los servicios existentes, producidos con recursos públicos, así como el suelo mediante la construcción en altura y el diseño de numerosos departamentos de dimensión reducida, en combinación con espacios comerciales y de servicios de oferta amplia, manteniendo la rentabilidad a pesar del alto 
costo del suelo. De esta forma se intensifica el uso de suelo mediante la verticalización con el objetivo de distribuir el precio del suelo entre un número elevado de compradores y realizar inversiones masivas de capital, cuya ganancia es distribuida entre el capital inmobiliario y el financiero, beneficiándose con los intereses cobrados a los compradores (Pradilla, 2018, p. 175). El diseño de estos desarrollos también garantiza que los habitantes de las viviendas, los usuarios de las oficinas y los huéspedes de los hoteles accedan a la oferta comercial del complejo, siguiendo la lógica del mercado y de la ganancia y respondiendo a los intereses especulativos del capital.

La concentración y diversificación de usos en los desarrollos mixtos les permite a los inversionistas captar significativas rentas del suelo de localización y monopolio acumuladas, y al término de la construcción, obtener rentabilidades futuras al comercializar, rentar, operar y/o administrar estos inmuebles multifuncionales convirtiéndolos en un negocio muy redituable. La rentabilidad y las ganancias a largo plazo han provocado la multiplicación de estos desarrollos en las principales ciudades de América Latina, por ejemplo: Las Torres Atrio, de 44 pisos (200 metros) y 59 pisos (268 metros) de alto, integradas por oficinas, servicios y comercios, diseñadas por Richard Rogers en el centro de Bogotá, Colombia; la Torre Brooklin, formada por oficinas, viviendas, hotel, comercio y servicios, con una altura de 230 metros, en Sao Paulo, Brasil; Costanera Center, complejo de usos mixtos integrado por cuatro edificios, uno de ellos, la Gran Torre Santiago, de 300 metros de altura, destinada a oficinas, en Santiago de Chile y la Torre Mítikah, desarrollo compuesto por tres torres de oficinas de 35 ,
35 y 27 niveles, una torre de departamentos de 65 pisos, con una altura de 265 metros, un hospital, un centro comercial y un hotel, en Ciudad de México; todas ellos, de reciente creación o en construcción, y los dos últimos diseñados por César Pelli.

Además, en los últimos años han surgido nuevas propuestas con mayor diversidad de uso, como los espacios "creativos" denominados co-living, co-working, la combinación de vivienda en renta y venta en un mismo inmueble, residencias de usos mixtos para adultos mayores, wellness centers, y espacios de oferta cultural y recreativa dentro de los centros comerciales, vivienda en renta Airbnb, entre otros (Herrera, 2018), que incrementan el juego especulativo.

La construcción de cada proyecto nuevo transforma el uso de suelo, por lo general el habitacional o el industrial, en terciario; en muchos casos, se logra la ejecución de programas de inversiones públicas dirigidas a reforzar y modernizar la infraestructura, que renuevan la imagen urbana e incrementan las rentas potenciales del suelo, basadas en un uso más lucrativo: comercial y de servicios de excelencia, al tiempo que atrae nuevas e innovadoras inversiones que simbolizan la urbanización global capitalista, cada vez más rentables y atractivas propiciando su multiplicación.

Aunque estos desarrollos inmobiliarios responden a una política de revitalización y compactación urbana, al aumentar la concentración de actividades necesarias para la reproducción social de la población, se generan nuevas dinámicas de crecimiento de flujos de capital, personas y mercancías; si esta intensificación del uso del suelo, no está acompañada de una planificación urbana 
integral e inversiones públicas correlativas, se generan externalidades negativas, que distan del objetivo inicial, por ejemplo: mayor densidad de población residente, trabajadora o usuaria en la zona; incremento de los déficits de infraestructura vial y de servicios (agua, drenaje, energía, recolección de desechos), aunque los nuevos inmuebles construidos sean sustentables; mayor demanda de transporte, congestionamiento vial y contaminación ambiental; los pequeños locales comerciales son sustituidos por grandes tiendas trasnacionales; la antigua arquitectura es reemplazada por otra "de marca", diseñada por arquitectos internacionales "posmodernos" contratados por las inmobiliarias multinacionales, que deja una estela de mercantilización cada vez más homogeneizadora (Harvey y Smith, 2005, p. 49).

Las características específicas de los nuevos desarrollos inmobiliarios, marcados por la selectividad territorial de las inversiones, la alta calidad de vida, la demanda de suelo comercial, la mercantilización y el consumo, elevan las rentas del suelo, el precio de los inmuebles y revalorizan el territorio, por lo tanto, son los sectores de altos ingresos quienes se benefician de la concentración de las nuevas actividades económicas, sociales y culturales, los inmuebles construidos y los espacios públicos revitalizados, mientras la elevación de los costos del suelo y de la vivienda en venta o renta, de los bienes y servicios y los impuestos prediales, afectan a los de bajos ingresos. Estas acciones elitizan el espacio, expulsan a sus antiguos residentes y segregan socio-territorialmente a los sectores de menor ingreso incapaces de acceder a los nuevos productos inmobiliarios, generando un cambio significativo de sector social residente y usuario, e intensificando la fragmentación del territorio.

\section{El Estado, la lógica neoliberal y la transformación urbana}

En el transito del patrón de acumulación con intervención estatal al neoliberal, el Estado sufrió profundas transformaciones. La aplicación de la política neoliberal implicó el debilitamiento del Estado mediante la desregulación de la vida económica; la privatización de las empresas e instituciones estatales; la reducción del gasto público, sobre todo el social; la reducción de la intervención del Estado en la producción y gestión de las condiciones generales para la reproducción de la población: infraestructura y servicios públicos - educación, salud, recreación, transporte, dotación de agua, entre otros -, mediante su rápida privatización y en muchos casos su desnacionalización, para dar paso a políticas dirigidas a la libre acción de la empresa privada nacional o trasnacional, la competencia, la privatización y mercantilización de lo público (Guillén, 1997; Pradilla, 2009; Márquez y Pradilla, 2017).

Estos procesos también involucraron a la política de construcción de vivienda pública y social, aplicada durante el periodo del Estado de bienestar social, desarticulándola, privatizándola y transformándola en mercancía y en activo financiero globalizado, mediante la generalización del crédito, incluyendo la inserción de sectores de medios y bajos ingresos en los circuitos financieros, la creación de nuevos productos vinculados 
al financiamiento del espacio construido, para promover la compra de casa propia en el mercado privado y convertir al individuo en consumidor de activos financieros; estas acciones abrieron una nueva frontera para depositar, valorizar y acumular el excedente de capital sobreacumulado, abandonando el papel de la política de vivienda como bien social y el de la ciudad como artefacto público (Rolnik, 2018).

El Estado, en la ideología y en la realidad, cambió sus funciones de interventor en aras del interés colectivo a facilitador o creador de condiciones para la libre empresa privada, incluida la planeación urbana (Pradilla, 2009, p. 207). En el ámbito territorial, las ciudades latinoamericanas dejaron a un lado la planeación urbana indicativa gestionada por el Estado y al mismo tiempo, orientaron su política económica y territorial hacia el camino de la terciarización, generando las condiciones para atraer inversiones inmobiliarias privadas nacionales e internacionales: megaproyectos y desarrollos inmobiliarios, obras de infraestructura y servicios, mediante la formulación de nuevos instrumentos como las alianzas público-privadas, las facilidades administrativas, los incentivos fiscales y/o la eliminación o simplificación de reglamentos o normas urbanas, que en el pasado fueron fundamentales en la aplicación de los planes de desarrollo urbano, normativos por naturaleza, durante el periodo del intervencionismo estatal (Pradilla, 2009, p. 208).

El periodo neoliberal se caracteriza por promover la competitividad urbana y la planeación estratégica basada en grandes acciones puntuales como metas del desarrollo urbano (Jaramillo, 2013, p. 300), en donde los megaproyectos urbanos y la aplicación de políticas de estímulo a la inversión se consideran el eje de la planeación. La aplicación de la forma de las Asociaciones Público Privadas (APP) a largo plazo, ha jugado un papel importante en el desarrollo urbano neoliberal, ya que permiten la realización de proyectos de coinversión entre los gobiernos y el sector privado, que evitan que los primeros utilicen recursos presupuestales o créditos para la construcción de obras, pero que entregan al capital inmobiliario-financiero el financiamiento, construcción, operación y mantenimiento de una obra pública.

Estas políticas neoliberales han impulsado una nueva dinámica de estructuración y crecimiento en las principales ciudades latinoamericanas, caracterizada por la terciarización de las actividades económicas y la multiplicación de megaproyectos o de altas torres destinadas a vivienda o servicios corporativos, que siguiendo la lógica del mercado, las ventajas de localización y de aglomeración y las rentas del suelo generadas, se asientan preferentemente en los bordes de las principales vialidades, contribuyendo a la formación de lo que Pradilla y Pino Ilaman, para la Zona Metropolitana del Valle de México, una Trama de Corredores Urbanos Terciarios (Pradilla y Pino, 2004; Pradilla y otros, 2008), entendidos como una concentración lineal de inmuebles que soportan mayoritariamente actividades terciarias privadas y/o públicas a lo largo de la vialidad o eje importante de flujos de vehículos, personas y mercancías.

En ellos se combinan múltiples soportes materiales como: centros comerciales y comercios aislados, tiendas departamentales, bancos, servicios financieros, hotelería, restaurantes, cafeterías, inmuebles para la cultura, deporte, educación, salud, oficinas, 
lugares de gestión pública y privada, servicios de transporte y comunicaciones, etc. Hay también la presencia minoritaria de establecimientos industriales, o desarrollos habitacionales que combinan usos de suelo mixto - comercio, hotelería, oficinas, servicios(Márquez, 2012). La formación de esta trama de corredores urbanos terciarios, con diversos grados de intensidad, consolidación, saturación, extensión y actividad terciaria, ha modificado la lógica de la estructuración urbana (Pradilla y Pino, 2004), en la cual es dominante el papel jugado por el capital inmobiliario-financiero. Las ventajas de aglomeración y localización generadas en los corredores, atraen hacia ellos a las nuevas inversiones inmobiliarias, en particular en centros comerciales y lugares de gestión, dando lugar a un "círculo virtuoso" para el capital comercial y el inmobiliario-financiero, que ha transformado la imagen urbana $y$, sobre todo, la lógica de estructuración urbana.

Este proceso se materializa en la conformación de corredores como Puerto Madero y el Corredor Norte del Gran Buenos Aires, en Buenos Aires, Argentina; las avenidas Paulista y Brigadeiro Faria Lima y el barrio Villa Olímpia en São Paulo, Brasil; la Costanera en Santiago de Chile; Paseo de la Reforma, Avenida Insurgentes y el Boulevard Adolfo López Mateos, entre otros, en Ciudad de México, México. Los tres últimos corredores urbanos mexicanos, los cuales destacan por su importancia dentro de la estructura urbana de la urbe, viven actualmente un boom inmobiliario.

Aunque el crecimiento inmobiliario del Paseo de la Reforma, la vialidad más importante y emblemática de la ciudad, data del año 2000 cuando se puso en marcha su programa de rescate, actualmente existen 14 desarrollos inmobiliarios, de los cuales siete se encuentran en construcción, tres en etapa de demolición y limpia de terreno y cuatro en calidad de proyecto; los cuales se suman a los 22 desarrollos inmobiliarios construidos y en funcionamiento en los últimos 18 años, entre los que destacan por su arquitectura y talla: Torre Mayor, Torre Reforma, St. Regis, Torre HSBC, Corporativo Bancomer, Reforma 222, Punta Reforma, entre otros.

En el tramo del Corredor Insurgentes que comprende de Boulevard Adolfo López Mateos (Periférico Sur) al Paseo de la Reforma, se registran 33 inmuebles en construcción, la mayoría de ellos destinados a la construcción de oficinas (18), ocho a vivienda, cinco a uso mixtos y dos a uso de suelo comercial. Así mismo, existen 10 predios baldíos y cinco inmuebles en proceso de demolición.

Sobre el Boulevard Adolfo López Mateos (Periférico), de la Glorieta de Vaqueritos al Paseo de la Reforma, se encuentran en construcción 30 edificios, 23 de ellos destinados a uso de suelo habitacional, cinco a complejos de oficinas y dos con información no disponible. En este corredor existen ocho predios baldíos o en proceso de demolición y/o excavación ${ }^{2}$ (Ver mapa 1).

\section{Comentarios finales}

El capital financiero resultó de la fusión del bancario con el industrial debido a la necesidad de éste de obtener dinero a crédito para financiar su inversión y producción. Desde su formación a fines del siglo XIX, la importancia del capital financiero ha 
Mapa 1 - Inmuebles en construcción en Corredores Urbanos Terciarios seleccionados de la Ciudad de México

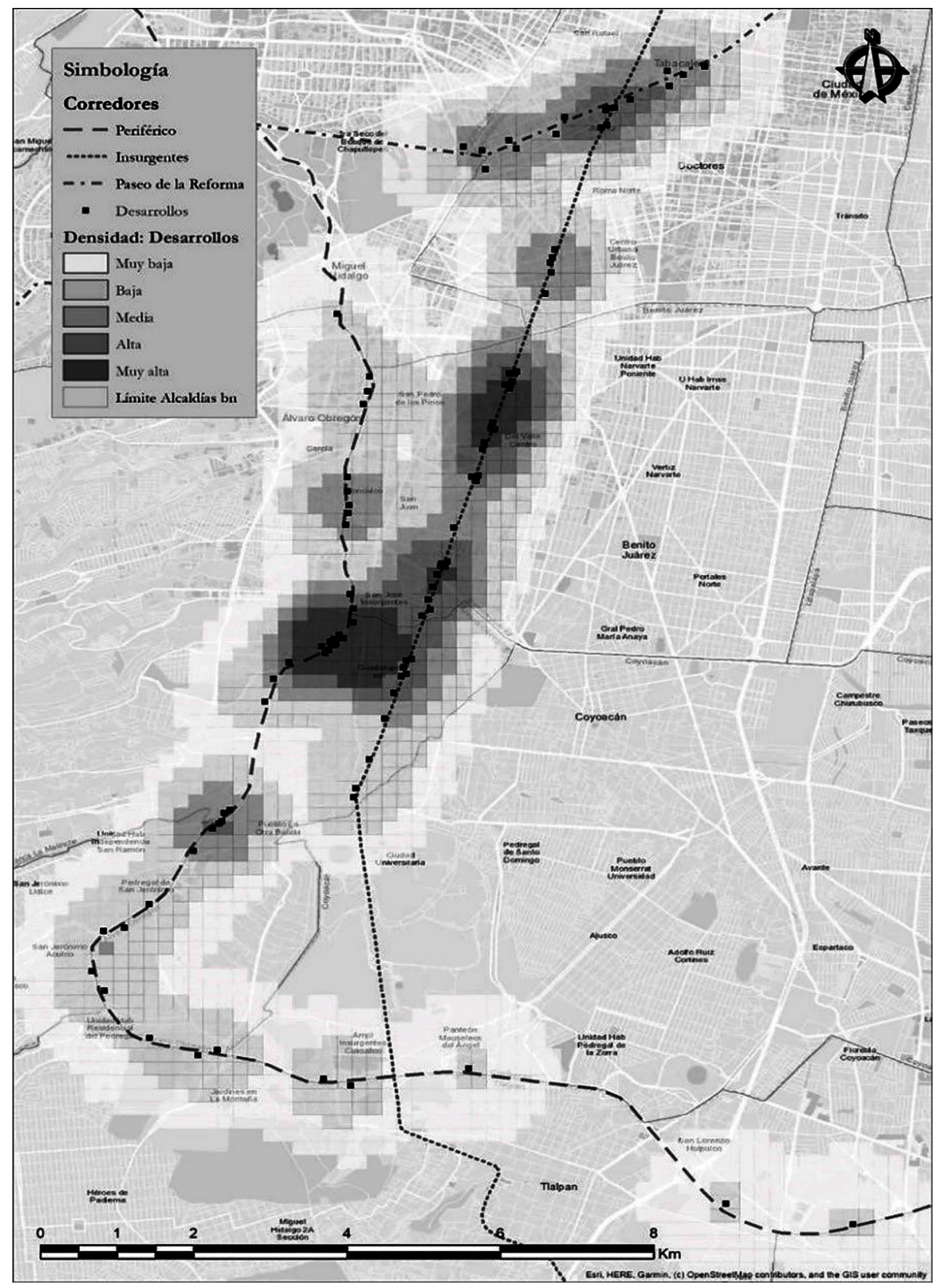

Fuente: elaboración propia con base en información obtenida mediante levantamiento realizado en marzo de 2019. Cartografía elaborada por Rafael Mora López, ayudante de investigación, UAM-X. 
crecido sin cesar, hasta penetrar en todos los rincones de la vida económica, incluyendo la reproducción de la población mediante las tarjetas de crédito, siendo hoy, la fracción dominante y hegemónica del capital en el sistema capitalista global.

Su fusión con el capital inmobiliario, cuyo objetivo es valorizar el capital mediante la producción y venta de los soportes materiales de la vida económico-social, se debe a dos condiciones estructurales de su funcionamiento: la larga duración del proceso constructivo que, por su fijación territorial, aparece como un ensamblaje en el sitio, sin posibilidades de industrializarse plenamente, y por ello, con un menor desarrollo de sus fuerzas productivas; y el mayor tiempo necesario para la realización del producto y la recuperación del capital invertido más la ganancia correspondiente a todos los actores capitalistas participantes, por el alto precio de venta del inmueble. El capital financiero provee de capital circulante para la producción de la mayor parte de los inmuebles, y cierra el ciclo del capital, devolviéndolo al momento de la producción, y llevar a cabo durante décadas la recuperación del precio de venta mediante el crédito hipotecario a los compradores.

Como el conjunto de la economía, la construcción y reconstrucción permanentes de las grandes ciudades se ha financiarizado, convirtiéndose en una de las formas fundamentales de colocación del capital-dinero sobreacumulado en las economías de los países hegemónicos y en productores de materias primas y bienes especializados como los grandes exportadores petroleros. Para lograr una mayor valorización del capital, el inmobiliario-financiero ha recurrido crecientemente a tácticas de alto riesgo como la securitización o titularización, entre otras, que han llevado a crisis como la ocurrida en 2008-2009.

En esta fase del capitalismo neoliberal, la facilitación subsidiaria otorgada por los gobiernos locales y nacionales, está presente en la construcción y reconstrucción de las grandes ciudades latinoamericanas: en la producción de vivienda de interés social en las periferias, generadora de dispersión y segregación urbana, y en la renovación mediante el despojo, le destrucción y la reconstrucción de grandes cantidades de inmuebles en áreas ya urbanizadas, como: centros comerciales, tiendas departamentales, torres de oficinas corporativas, vivienda de lujo, y hotelería, e infraestructura y servicios públicos mediante asociaciones públicoprivadas, dando lugar a ciudades segregadas y fragmentadas por la localización diferenciada de estratos sociales y sus condiciones de vida urbana.

En la subordinación del Estado al mercado y al capital privado, la planeación territorial indicativa ha cedido el lugar a la estratégica, a la manera empresarial, basada en los grandes proyectos urbanoarquitectónicos propuestos y realizados por el capital inmobiliario-financiero privado.

Los despojos frecuentes de los habitantes populares en las áreas centrales, las continuas violaciones de las inmobiliarias a las limitadas normas, las afectaciones al patrimonio y la habitabilidad de todos los habitantes en las áreas de intervención, el engaño en la venta de viviendas sociales carentes de servicios básicos, inhabitables y a gran distancia de las áreas de trabajo, servicios sociales y recreativos, provocan una conflictividad urbana, para cuya superación se 
requiere del empoderamiento de los vecinos de las áreas centrales, y los compradores potenciales de la vivienda de interés social, que cada vez con mayor énfasis reclaman el derecho a la ciudad; y de la reconstrucción de una planeación urbana democrática, participativa, equitativa y justa, integrada para toda la ciudad, y que imponga normas estrictas al capital inmobiliario-financiero y castigue rigurosamente sus violaciones.

\section{[1] https://orcid.org/0000-0003-4626-0361}

Universidad Autónoma Metropolitana, División de Ciencias y Artes para el Diseño, Departamento de Teoría y Análisis. Unidad Xochimilco, México.

lismarq@hotmail.com

\section{Notas}

(1) Parnreiter entiende a la financiarización como "el proceso de desviar el capital de la economía "real" (la producción y el comercio) para luego mantenerlo en su forma más flexible como capital-dinero líquido"(Parnreiter, 2018, p. 473).

(2) Información obtenida mediante levantamientos realizados en marzo de 2019 por la autora de este trabajo.

\section{Referencias}

BBVA RESEARCH (2018). Situación inmobiliaria México. Segundo semestre de 2018. Disponible en: https://www.bbvaresearch.com/publicaciones/situación-inmobiliaria-mexico-segundosemedtre-2018/. Acceso el: 6 jul 2019.

CARNET (1990). El dinero de plástico: historia del crédito al consumidor y de los nuevos sistemas de pago en México. México, J. R Fortson Editorial.

COLLING, A. (1965). Historia de la banca, de Babilonia a Wall Street. Barcelona, Zeus.

DAVID, L. (2017). "El desarrollador-plataforma", nuevo actor de la división del trabajo inmobiliario financiarizado en México. Estudios demográficos y urbanos. Distrito Federal, v. 32, n. 2, pp. 225-244.

DE MATTOS, C. (2016). Financiarización, valorización inmobiliaria del capital y mercantilización de la metamorfosis urbana. Sociologias. Porto Alegre, v. 1, n. 42, pp. 24-52.

(2018). Encrucijada ante los impactos de un crecimiento urbano financiarizado. Instituto de Estudios Urbanos y Territoriales, Documentos de Trabajo. Santiago de Chile, Pontificia Universidad Católica de Chile.

DOMÍNGUEZ, J.; FERNANDINI, M.; RIQUELME, L.; SCHNEIDER, C. (2017). Financiamiento del mercado de vivienda en América Latina y el Caribe. Banco Interamericano de Desarrollo.

GUILLÉN ROMO, H. (1997). La contrarrevolución neoliberal. México. Distrito Federal, Era. 
HARVEY, D. (2007). El nuevo imperialismo. Madrid, Akal.

(2013). Ciudades rebeldes. Del derecho a la ciudad a la revolución urbana. Madrid, Akal.

HARVEY, D.; SMITH, N. (2005). Capital financiero, propiedad inmobiliaria y cultura. Barcelona, Universidad Autónoma de Barcelona.

HERRERA, M. (2018). Desarrollo de usos mixtos complejos. Disponible en: https://inmobiliare.com/ desarrollos-de-usos-mixtos-complejos/. Acceso el: 8 jul 2019.

HUERTA, G.; KALA, J. C. (2013). “El fenómeno de la financiarización y la operación de Cemex, Gruma y Vitro en el contexto de la crisis financiera internacional". In: LEVY, N.; LÓPEZ, T. (comps.). Financiarización y modelo de acumulación. Aportes desde los países en desarrollo. México, Distrito Federal, Universidad Nacional Autónoma de México.

JARAMILLO, S. (2009). Hacia una teoría de la renta del suelo urbano. Bogotá, Universidad de los Andes.

(2013). “Acerca de la investigación en mercados de tierra urbana en América Latina". In: RAMÍREZ B.; PRADILLA, E. Teorías sobre la ciudad en América Latina. México, Distrito Federal, Universidad Autónoma Metropolitana.

LÓPEZ, P.; ROUGIER, M. (2018). “Luces y sombras de las experiencias de banca de desarrollo en América Latina durante los procesos de industrialización”. In: FUENTES, D. (ed.). Orígenes de la globalización bancaria. Experiencias de España y América Latina. México, Distrito Federal, El Colegio de México.

LÓPEZ, T.; BUSTAMANTE, J. (2013). “Alta rentabilidad y financiarización de las ganancias de las grandes empresas en México: estructura de la deuda y origen de las ganancias". In: LEVY, N.; LÓPEZ, T. (comps.). Financiarización y modelo de acumulación. Aportes desde los países en desarrollo. México, Distrito Federal, Universidad Nacional Autónoma de México.

MÁRQUEZ, L. (2005). La desindustrialización del Área Metropolitana de la Ciudad de México. Tesis de Maestría. México, Distrito Federal, Instituto de Investigaciones Dr. José María Luis Mora.

(2012). Cambios en la estructura urbana y formación de un corredor urbano terciario. Paseo de la Reforma 1970-2007. Tesis de doctorado. México, Distrito Federal, Universidad Nacional Autónoma de México.

MÁRQUEZ, L.; PRADILLA, E. (2008). Desindustrialización, terciarización y estructura metropolitana: un debate conceptual necesario. Cuadernos del CENDES. Caracas, v. 25, n. 69, pp. 21-45.

(2017). “La privatización y mercantilización de lo urbano”. In: HIERNAUX, D.; GONZÁLEZ, C. La ciudad latinoamericana a debate. Perspectivas teóricas. Querétaro, Universidad Autónoma de Querétaro.

ONU - Organización de Naciones Unidas (2017). Nueva Agenda Urbana, Hábitat III. Ecuador.

PARNREITER, C. (2018). Geografía económica: una introducción contemporánea. Ciudad de México, Universidad Nacional Autónoma de México

PRADILLA, E. (2009). Los territorios del neoliberalismo en América Latina. México, Distrito Federal. Miguel Ángel Porrúa, Universidad Autónoma Metropolitana.

(2010). Teorías y políticas urbanas, ¿Libre mercado mundial o constitución regional? Revista Brasileira de Estudos Urbanos e Regionais. São Paulo, v. 12, n. 2, pp. 9-21. 
PRADILLA, E. (2018). "Formas productivas, fracciones del capital y reconstrucción urbana en América Latina”. In: CORAGGIO, J. L.; MUÑOZ, R. (coords.). Economía de las ciudades en América Latina hoy, Enfoques multidisciplinarios. Buenos Aires, Universidad Nacional de General Sarmiento.

PRADILLA, E.; MÁRQUEZ, L.; CARREÓN, S.; FONSECA, E. (2008). Centros comerciales, terciarización y privatización de lo público. Ciudades. Puebla, n. 79, pp. 44-53.

PRADILLA, E.; PINO, R. (2004). Ciudad de México: de la centralidad a la red de corredores urbanos. Anuario de Espacios Urbanos 2004. Distrito Federal, pp. 71-96.

ROLNIK, R. (2017). La guerra de los lugares. La colonización de la tierra y la vivienda en la era de las finanzas. Santiago de Chile, LOM.

SASSEN, S. (1999). La ciudad global. Nueva York, Londres, Tokio. Buenos Aires, Eudeba, Universidad de Argentina.

TOLENTINO, J. (2017). Crowdfunding inmobiliario desde Nueva York para el mundo. Disponible en: https://www.eleconomista.com.mx/finanzaspersonales/Crowdfunding-inmobiliario-desdeNueva-York-para-el-mundo-20170918-0053.html. Acceso el: 4 jul 2019.

TOPALOV, C. (1979). La urbanización capitalista: algunos elementos para su análisis. México, Distrito Federal, Edicol.

VALENCIA, N. (2018). ¿Qué fue del BD Batacá, el rascacielos más alto de Colombia? Disponible en: https://www.archdaily. $\mathrm{mx} / \mathrm{mx} / 892008 / q u e-f u e-d e l-b d$-bacata-el-rascacielos-mas-alto-decolombia. Acceso el: 4 jul 2019.

Texto recebido em 17/fev/2020

Texto aprovado em 17/abr/2020 